\title{
Transmittance of Airborne Laser Scanning Pulses for Boreal Forest Elevation Modeling
}

\section{Eero Ahokas ${ }^{1}$ *, Juha Hyyppä ${ }^{1}$, Xiaowei Yu ${ }^{1}$ and Markus Holopainen ${ }^{2}$}

1 Finnish Geodetic Institute, Geodeetinrinne 2, FI-02431 Masala, Finland;

E-Mails: juha.hyyppa@fgi.fi (J.H.); yu.xiaowei@fgi.fi (X.Y.)

2 Department of Forest Resource Management, University of Helsinki, Latokartanonkaari 7 , FI-00014 Helsinki, Finland; E-Mail: markus.holopainen@helsinki.fi

* Author to whom correspondence should be addressed; E-Mail: eero.ahokas@fgi.fi;

Tel.: +358-9-295-55-201; Fax: +358-9-295-55-200.

Received: 4 May 2011; in revised form: 22 June 2011 / Accepted: 24 June 2011 /

Published: 4 July 2011

\begin{abstract}
The transmittance of laser pulses through the forest canopy was studied as a function of forest attributes (inventory parameters) and the scanning angle from the point of view of elevation modeling. Here transmittance is defined as the ratio of the number of pulses within a threshold of the detected elevation model to the total number of transmitted pulses. Airborne laser scanning (ALS) using a Leica ALS50-II scanner took place on 25 July 2009 in the Evo test area in Southern Finland. The total number of circular field test plots with a radius of 10 meters was 246 . Several of the test plots were observed from two different flight lines, and this resulted in 454 observations. Multiple regression analysis was applied to calculate statistical parameters for the scanning angle and the forest attributes. The canopy layer is an important factor that influences the number of ground hits. We found that the characteristics of the trees determine the number of transmitted pulses penetrating down to the ground level. When using scanning angles between 0 to 15 degrees in forested areas, the results showed that the scanning angle did not have a statistically significant effect on the vegetation penetration nor on the number of ground hits. It appears to be feasible to increase the scanning angle for boreal forest elevation modeling if some degree of local shadowing can be accepted in the data. By increasing the scanning angle, it is also possible to perform laser scanning and digital aerial photography simultaneously even over forested areas. Nationwide laser scanning in Finland and Sweden is carried out with scanning angles of \pm 20 degrees, but further studies are needed to assess the results when using even larger scanning angles.
\end{abstract}


Keywords: airborne laser scanning; scanning angle; transmittance

\section{Introduction}

When a laser beam hits the forest canopy non-vertically, the other side of the canopy objects is partly or totally shadowed and there are areas on the ground receiving no hits or only a small number of hits (shadowing effect). Similarly in urban mapping with airborne laser scanner (ALS), the facades of buildings in built-up environments and ground elevations cannot be obtained from shadowed areas. Thus, shadowing causes problems in the 3-D reconstruction of buildings and trees as well as when determining Digital Terrain/Elevation Models (DTM/DEM). At the time of the advent of airborne laser scanning, the shadowing problem was considered to be a serious challenge. The TopoSys airborne laser scanner was designed to include a scanning angle of \pm 7.1 degrees off-nadir in order to minimize shadow formation [1]. Since then, laser scanning has been applied to tasks such as the creation and updating of nationwide elevation models and standwise forest inventories where data covering large areas need to be collected cost-efficiently. Presently, scanning angles of \pm 15 degrees have been generally accepted in operational work, but larger scanning angles are also applied, e.g., in Finnish and Swedish nationwide airborne laser scanning, the corresponding scanning angle is \pm 20 degrees.

The accuracy of elevation models and forest inventory products is relatively well known as regards the application of airborne laser scanning in boreal forests [2-7], and the associated filtering techniques have been adequately reported (e.g., [8,9]). The works of Reutebuch et al. [4] and Hyyppä et al. [10] can be recommended as overviews of the elevation model's accuracy. Using TopEye MK I laser scanner data with 4 pulses per $\mathrm{m}^{2}$, Reutebuch et al. [4] reported elevation random errors of $14 \mathrm{~cm}$ for boreal forest clear-cuts, $14 \mathrm{~cm}$ for heavily-thinned forest, $18 \mathrm{~cm}$ for lightly-thinned forest, and $29 \mathrm{~cm}$ for uncut forest. Variation in ALS-derived DEM quality with respect to date, flight altitude, pulse mode, terrain slope, forest cover, and within-plot variation was reported by Hyyppä et al. [10].

Ahokas et al. [11] mentioned that the optimization of the scanning angle (i.e., field of view) is an important part of nationwide airborne laser scanning. Significant savings in flying time (and thus in costs) can be achieved by increasing the scanning angle and flight altitude. The initial results obtained using scanning angle analysis showed that the scanning angle had an impact on the accuracy of DEMs, but that other factors, such as forest density, dominate the process. Scanning angles up to 15 degrees appear to be usable in DEM production in high-altitude laser scanning within the boreal forest zone. High-altitude laser scanning yielded an accuracy of about $\pm 20 \mathrm{~cm}$ (std), which is good enough for most terrain models in forested areas. Ahokas et al. [11] stressed that the impact of the scanning angle should be studied further for elevation modeling as the maximum field of view of commercial laser scanners can be up to 75 degrees (i.e., maximum scanning angle up to 37.5 degrees).

$\mathrm{Su}$ et al. [12] analyzed the influence of vegetation, slope, and the sampling angle in airborne laser scanning (the laser beam angle from nadir) on DEM accuracy. Vegetation was the greatest source of error in the LiDAR (Light Detection And Ranging) -derived elevation model. Closed and semi-open aspen forest had the greatest signed (+) errors and lowland meadows the greatest (-) errors. ALS should be done in early spring or late autumn in order to mitigate the effect of vegetation. It was also 
reported that DEM accuracy decreased when the slope gradient increased. The off-nadir scanning angles should be less than 15 degrees to minimize the errors introduced by steep slope gradients. The LiDAR sampling angle had little impact on the measured error and it was not important. Holmgren et al. [13] simulated the effects of LiDAR scanning angle for the purpose of estimating mean tree height and canopy closure. Simulations revealed that the laser height percentiles and the proportion of canopy returns changed more with an increased scanning angle for long-crowned species like Norway spruce, compared with short-crowned species like Scots pine. Also, the proportion of canopy returns was affected by scanning angle more than the laser height percentiles were. Chasmer et al. [5] investigated laser pulse penetration through a conifer canopy by integrating airborne and terrestrial LiDAR. They found that pulses with higher energy penetrated further into the canopy. The authors suggest that future research should concentrate on improving the understanding of how laser-pulse returns are triggered within vegetated environments and how canopy properties influence the location of the trigger event. Morsdorf et al. [14] assessed the influence of flying altitude and scanning angle on biophysical vegetation products (tree height, crown width, fractional cover, and leaf area index) derived from airborne laser scanning. Due to the small scanning angle of the TopoSys Falcon II ( \pm 7.15 degrees), the dependence of airborne laser scanning on the incidence angle is not so evident. The angle of incidence (the angle to the surface normal of the horizontal plane) appears to be of greater importance for vegetation density parameters than the local angle of incidence (the angle to the surface normal in the elevation model). The local topography is, thus, less important than the scanning angle. ALS data from larger scanning angles should be used to study further the impact of the scanning angle on vegetation density products. Ahokas et al. [15] showed that laser-beam transmittance through the canopy of a small group of Norway spruce trees is a non-linear function of biomass based on the results of an indoor experiment. The scanning angle had only a minor impact on the results when compared to changes in the biomass. Scanning angles of up to 38 degrees proved to be feasible for elevation mapping in this indoor experiment. It was proposed that airborne experiments need to be continued in this subject area.

This being so, the present paper tells of research on the transmittance of laser pulses through the forest canopy as a function of forest attributes (inventory parameters) and the scanning angle from the point of view of elevation modeling. Transmittance was defined as the ratio of the number of pulses within a threshold of the detected elevation model to the total number of transmitted pulses. The motivation for the study is in that if the scanning angle impact on transmittance is minor, then a larger scanning angle range can be accepted in future in applications where small shadowed areas can be accepted as long as the average number of ground hits is also acceptable.

\section{Material and Methods}

\subsection{Test Site}

The Evo test area is located in Southern Finland, some $100 \mathrm{~km}$ north of Helsinki. The field measurements were conducted in 2007 on this boreal forest site. A detailed description of the study area and the field measurements can be found in [16]. The average stand size is less than 1 ha in this managed boreal forest covering about 2000 ha. The proportion of Scots pine (Pinus sylvestris) is 40\%, 
that of Norway spruce (Picea abies) is $35 \%$, and that of deciduous trees (mainly birch, Betula spp.) is $24 \%$ of the total stem volume (hereafter: volume). The altitude of the site varies between $125 \mathrm{~m}$ and $185 \mathrm{~m}$ above sea level.

\subsection{Applied Systems and Data Collection}

\section{Laser Data}

The laser scanning took place on 25 July 2009 between 8:15 and 11:40, and 12:35 and 15:20 UTC. The Leica ALS50-II scanner was operated by staff of FM-International Ltd. The scanning parameters were as follows: opening angle 30 degrees, side lap 20\%, flight altitude $400 \mathrm{~m}$ above ground level, speed 80 knots, scanning frequency $52.2 \mathrm{~Hz}$, and pulse rate $150 \mathrm{kHz}$. The swath width of the strip was about $210 \mathrm{~m}$. The registered echoes of the laser pulses can be divided into classes: first of many, intermediate, last of many, and only. The number of sent pulses can be obtained by summing the first and only pulses. The point densities for the first and only pulses were $16-17$ points $/ \mathrm{m}^{2}$ for all points along the strip and $10-14$ points $/ \mathrm{m}^{2}$ in the middle of the swath.

\section{Field data}

The plot centers were measured using a Trimble GEOXM 2005 GPS (Global Positioning System) device and each tree was positioned by measuring its direction and distance from the plot center. The plot radius was $10 \mathrm{~m}$, giving a plot size of $314 \mathrm{~m}^{2}$. Altogether, 246 field plots were available for this study. The tree heights were measured using a hypsometer. The tree diameters were also needed to calculate the volume of each tree, and the $\mathrm{DBH}$ (diameter at breast height) of all trees having a DBH exceeding $5 \mathrm{~cm}$ was measured using steel calipers. The stem volumes were calculated using standard Finnish models [17]. The measurement results for the field plots are shown in Table 1. The field measurements were conducted in 2007 and the laser scanning in 2009.

Table 1. Characteristics of the Evo field plots [16].

\begin{tabular}{lcccc}
\hline & Mean & Min & Max & St.dev \\
\hline Basal area-weighted mean height $(\mathrm{m})$ & 17.0 & 0 & 30.5 & 6.7 \\
Basal area-weighted mean DBH $(\mathrm{cm})$ & 21.1 & 0 & 50.3 & 9.4 \\
Basal area $\left(\mathrm{m}^{2} / \mathrm{ha}\right)$ & 19.9 & 0 & 45.5 & 10.3 \\
Mean volume of growing stock $\left(\mathrm{m}^{3} / \mathrm{ha}\right)$ & 179.0 & 0 & 575.4 & 115.4 \\
Mean volume of Scots pine $\left(\mathrm{m}^{3} / \mathrm{ha}\right)$ & 69.9 & 0 & 560.6 & 89.8 \\
Mean volume of Norway spruce $\left(\mathrm{m}^{3} / \mathrm{ha}\right)$ & 63.5 & 0 & 575.4 & 94.8 \\
Mean volume of deciduous trees $\left(\mathrm{m}^{3} / \mathrm{ha}\right)$ & 42.9 & 0 & 302.2 & 51.2 \\
Mean volume of other tree species $\left(\mathrm{m}^{3} / \mathrm{ha}\right)$ & 2.7 & 0 & 210.1 & 19.0 \\
\hline
\end{tabular}




\subsection{Data Preprocessing}

The laser data were calibrated strip-by-strip by the data provider using the TerraMatch software. A common heading $(\mathrm{H})$, roll $(\mathrm{R})$, pitch $(\mathrm{P})$, and mirror scale correction were applied first, and then a heading, roll, pitch (HRP) correction was implemented by flight line. A height correction (dZ) was applied by flight line in the third phase. The ground surface was classified using the TerraScan software.

\subsection{Analysis Methods}

The same field test plots (246) were observed from different flight lines (trajectories), and this meant that the total number of observations was 454 . The ground surface was classified using the TerraScan software. The method used in the ground classification can be found in [18]. Since TerraScan finds the key points for the elevation models, there were three ground surface tolerance levels around the TerraScan-found TIN: $\pm 0.25 \mathrm{~m}, \pm 0.50 \mathrm{~m}$, and $\pm 1.0 \mathrm{~m}$, and we assumed that all points within these tolerance levels were considered as ground hits for transmittance calculations.

The mean scanning angle was the average of the minimum and maximum angles hitting the plot. Each plot was characterized by the mean height of the trees, their mean diameter, basal area, and volume. All of the plot data (transmittances, mean angle, forest parameters) of the 454 observations were combined into one Excel file sheet and sorted by applying plot-wise mean scanning angle for the further statistical analysis.

Multiple regression analysis was used to calculate the coefficient of determination $\left(\mathrm{R}^{2}\right)$ for the mean scanning angle, the mean height of the trees, their mean diameter, their mean basal area, and the stand volume. The dependent variable was the transmittance $(\mathrm{Tr})$ of the laser pulse to the ground at three tolerance levels: within ground surface $\pm 0.25 \mathrm{~m}, \pm 0.50 \mathrm{~m}$, and $\pm 1.0 \mathrm{~m}$.

The linear models used were:

Tr._tolerance_level $=\mathrm{b} 0+\mathrm{b} 1 *$ Angle $+\mathrm{b} 2 * \operatorname{Height}(\mathrm{m})+\mathrm{b} 3 * \operatorname{Diameter}(\mathrm{cm})+\mathrm{b} 4 *$ Basal_area $(\mathrm{m} 2 / \mathrm{ha})$ $+\mathrm{b} 5 * \operatorname{Volume}\left(\mathrm{m}^{3} / \mathrm{ha}\right)$

Ln Tr._tolerance_level $=\mathrm{b} 0+\mathrm{b} 1 *$ Angle $+\mathrm{b} 2 * \operatorname{Height}(\mathrm{m})+\mathrm{b} 3 * \operatorname{Diameter}(\mathrm{cm})+$ $\mathrm{b} 4 *$ Basal_area $\left(\mathrm{m}^{2} / \mathrm{ha}\right)+\mathrm{b} 5 * \operatorname{Volume}\left(\mathrm{m}^{3} / \mathrm{ha}\right)$

\section{Results and Discussion}

When looking at the relationship between the transmittance and the scanning angle, Figures 1-3 depict how the transmittance of laser pulses through the canopy of a boreal forest occurs in relation to the scanning angle. The angles are negative to left of the flight line and positive to the right. As can be seen from the figures and from the coefficients of determination $\left(\mathrm{R}^{2}\right)$, which are very small $(0.0001$ to 0.008), there is basically no correlation between the transmittance and the scanning angle when examining this data set. 
Figure 1. Transmittance scatter of the laser pulses through the canopy of a boreal forest across the scanning angle. Ground tolerance level $\pm 0.25 \mathrm{~m}$.

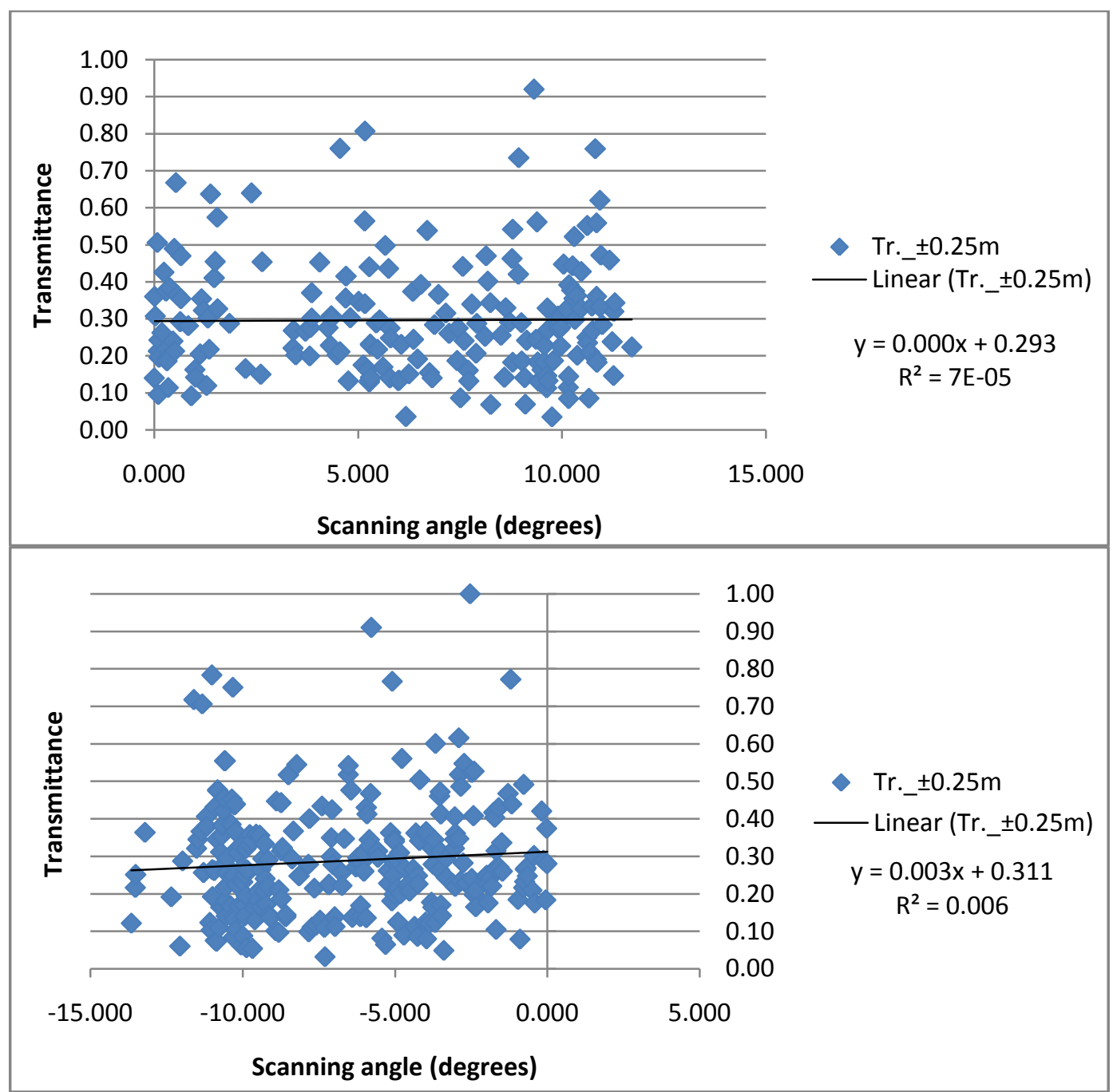

Figure 2. Transmittance scatter of the laser pulses through the canopy of a boreal forest across the scanning angle. Ground tolerance level $\pm 0.5 \mathrm{~m}$.

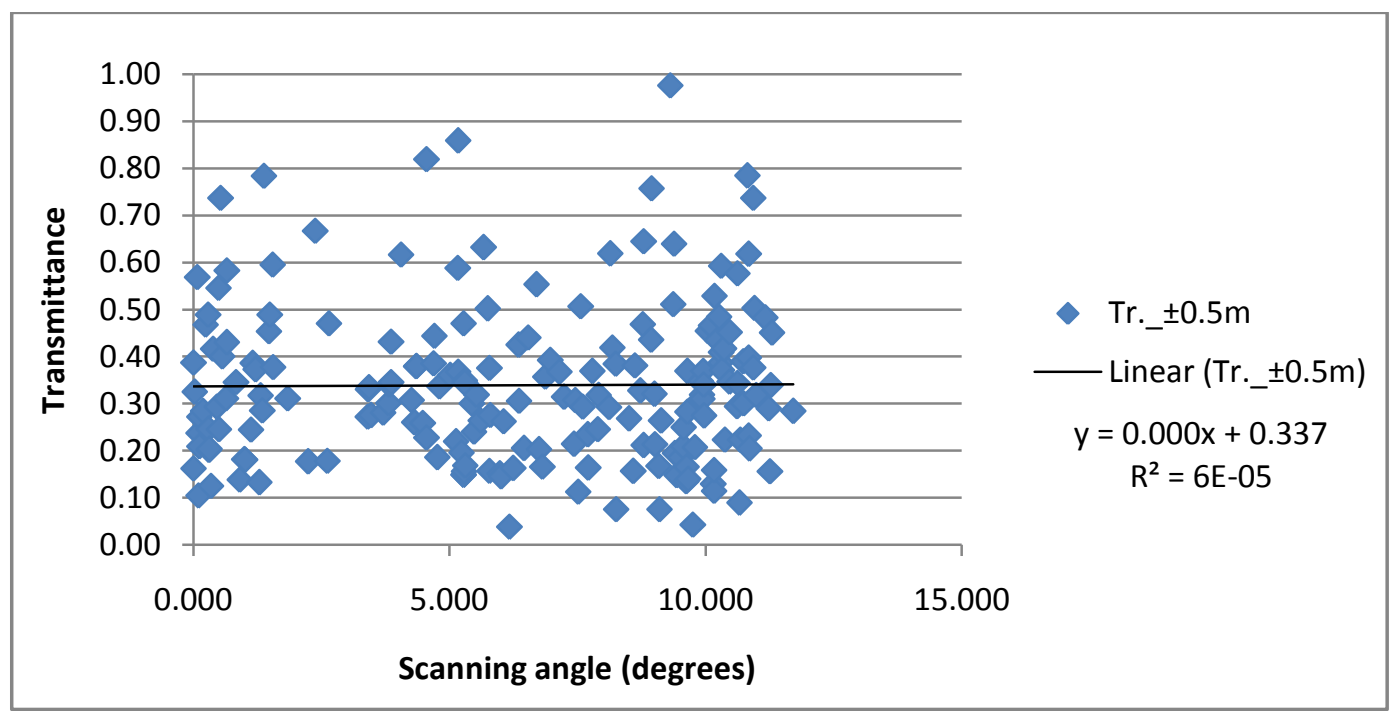


Figure 2. Cont.

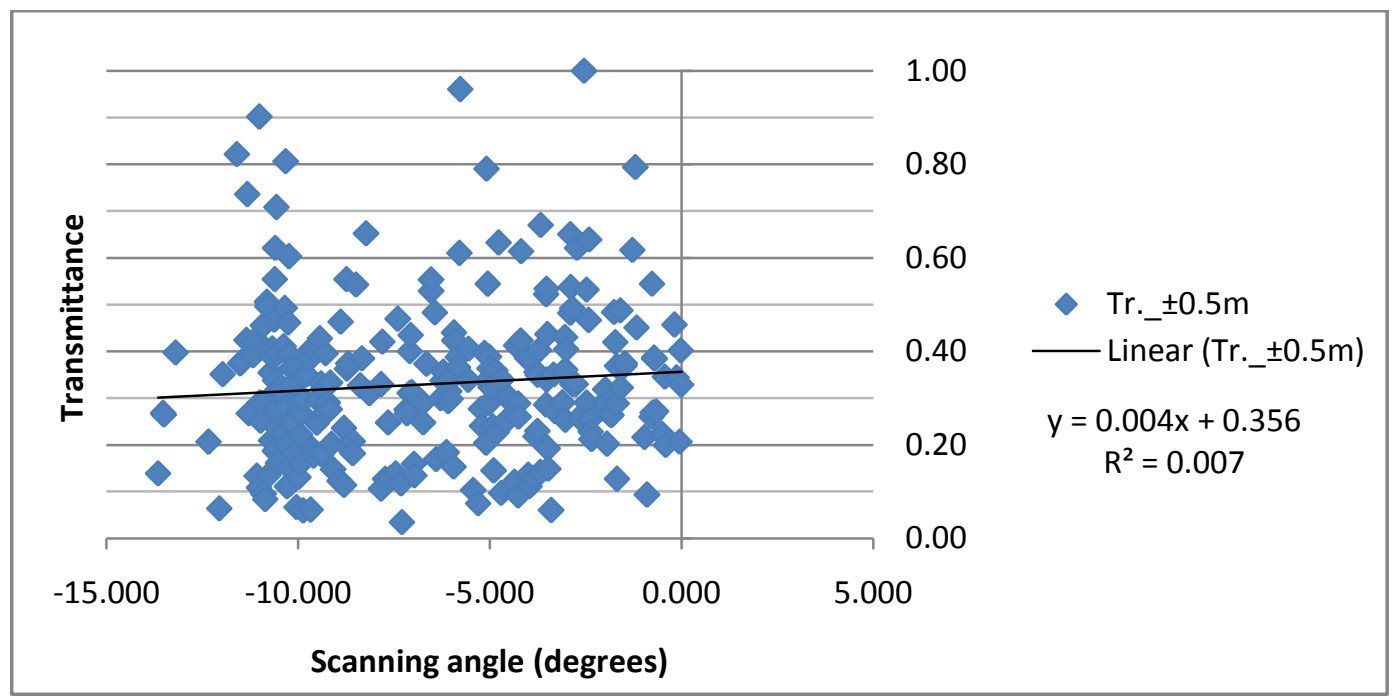

Figure 3. Transmittance scatter of the laser pulses through the canopy of a boreal forest across the scanning angle. Ground tolerance level $\pm 1.0 \mathrm{~m}$.

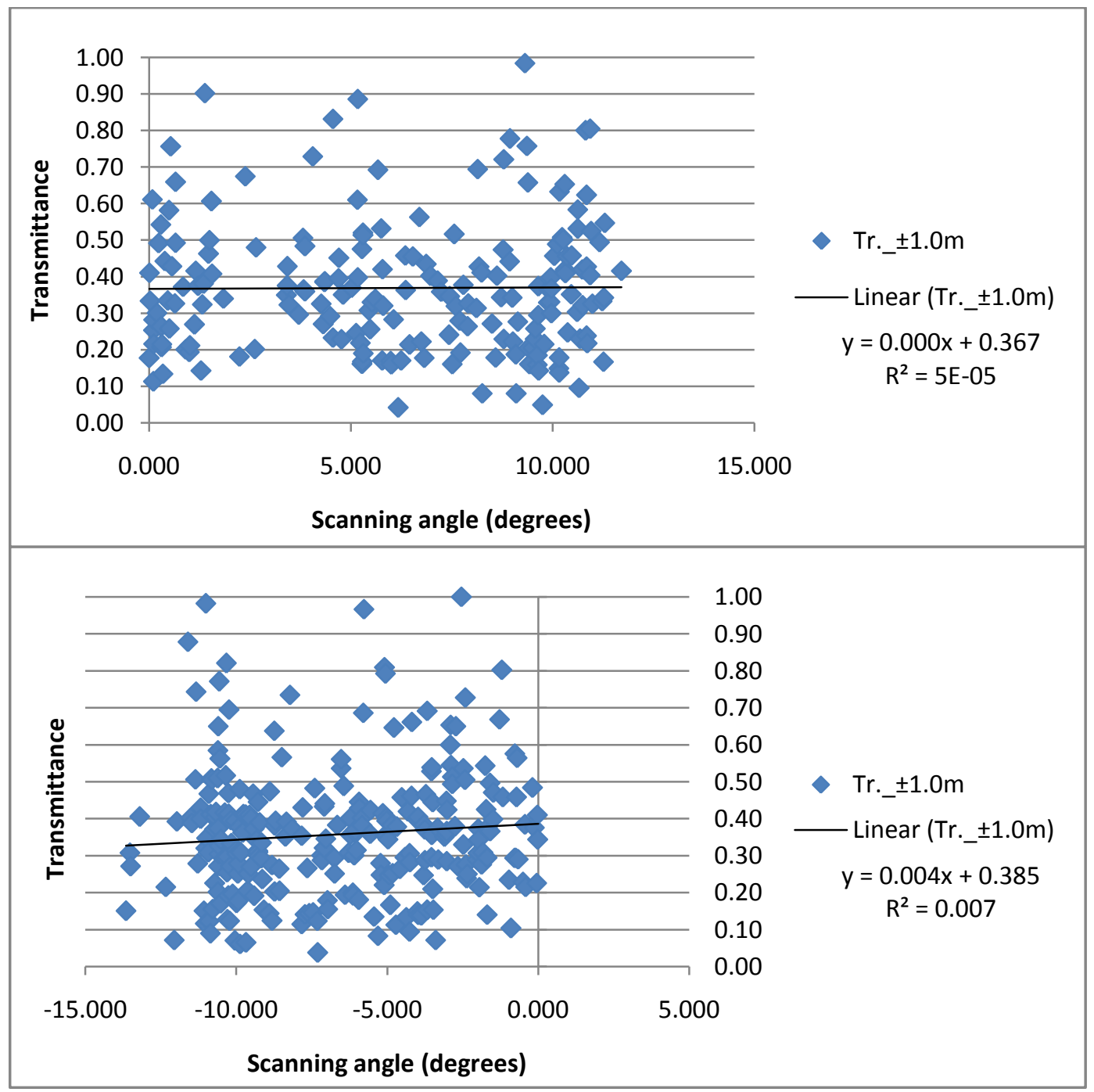


As the scanning angle has only a minor impact on the transmittance of laser pulses through the forest canopy, transmittance was further studied as a function of the stem volume.

Figure 4. Transmittance through the canopy to the ground as a function of stem volume.

Ground tolerance level $\pm 0.25 \mathrm{~m}$.

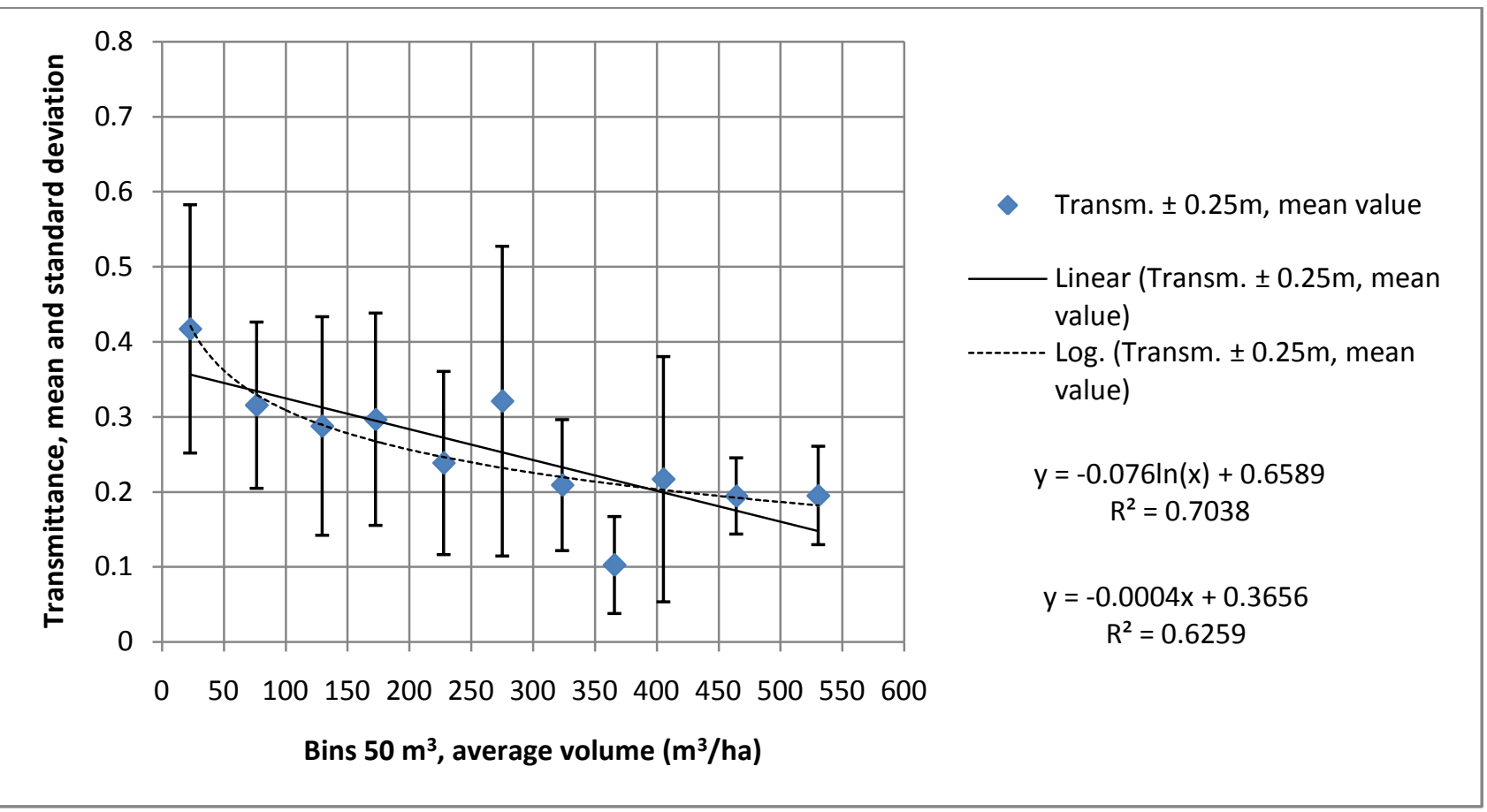

Figure 5. Transmittance through the canopy to the ground as a function of stem volume. Ground tolerance level $\pm 0.5 \mathrm{~m}$.

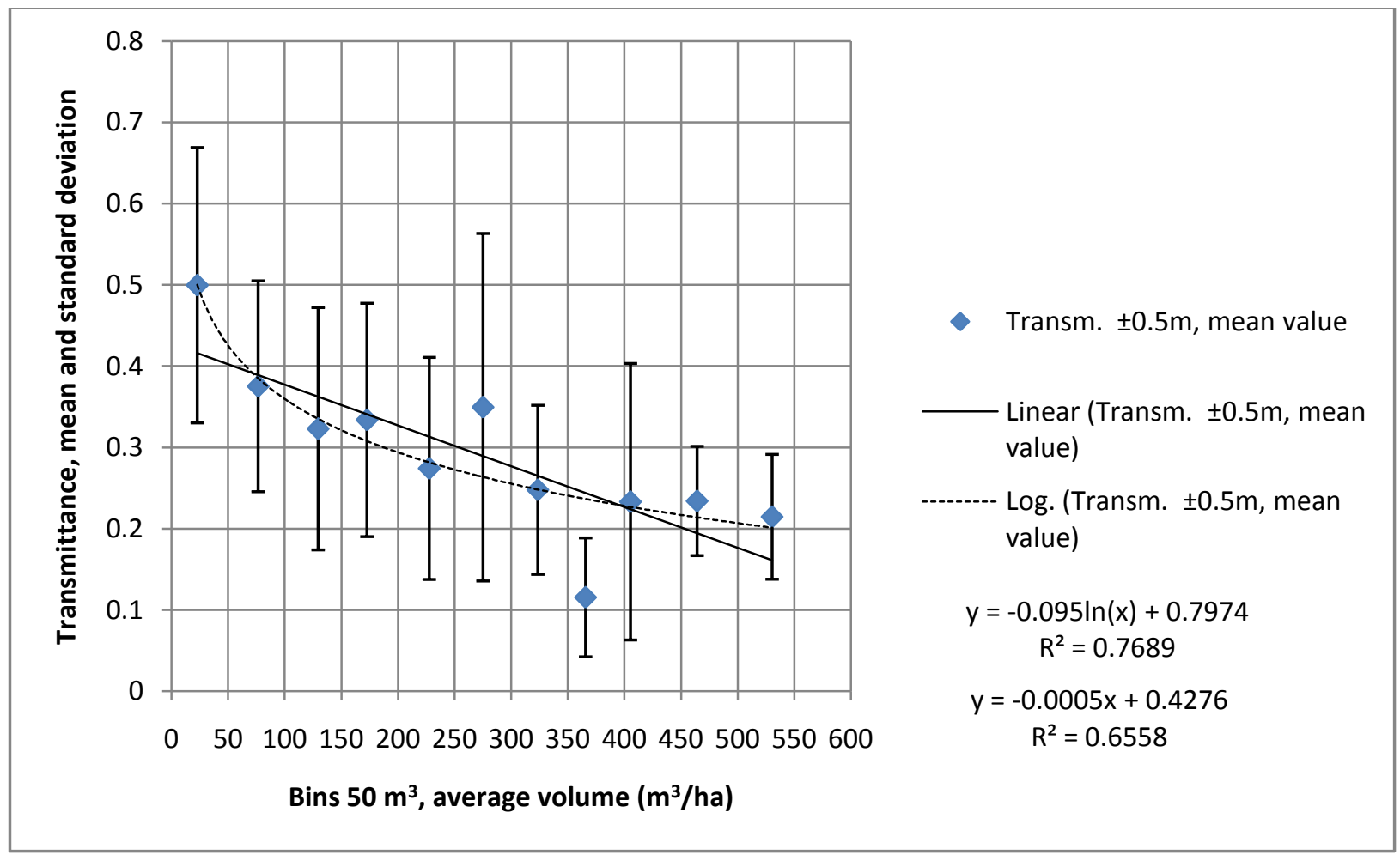


Figure 6. Transmittance through the canopy to the ground as a function of stem volume. Ground tolerance level $\pm 1.0 \mathrm{~m}$.

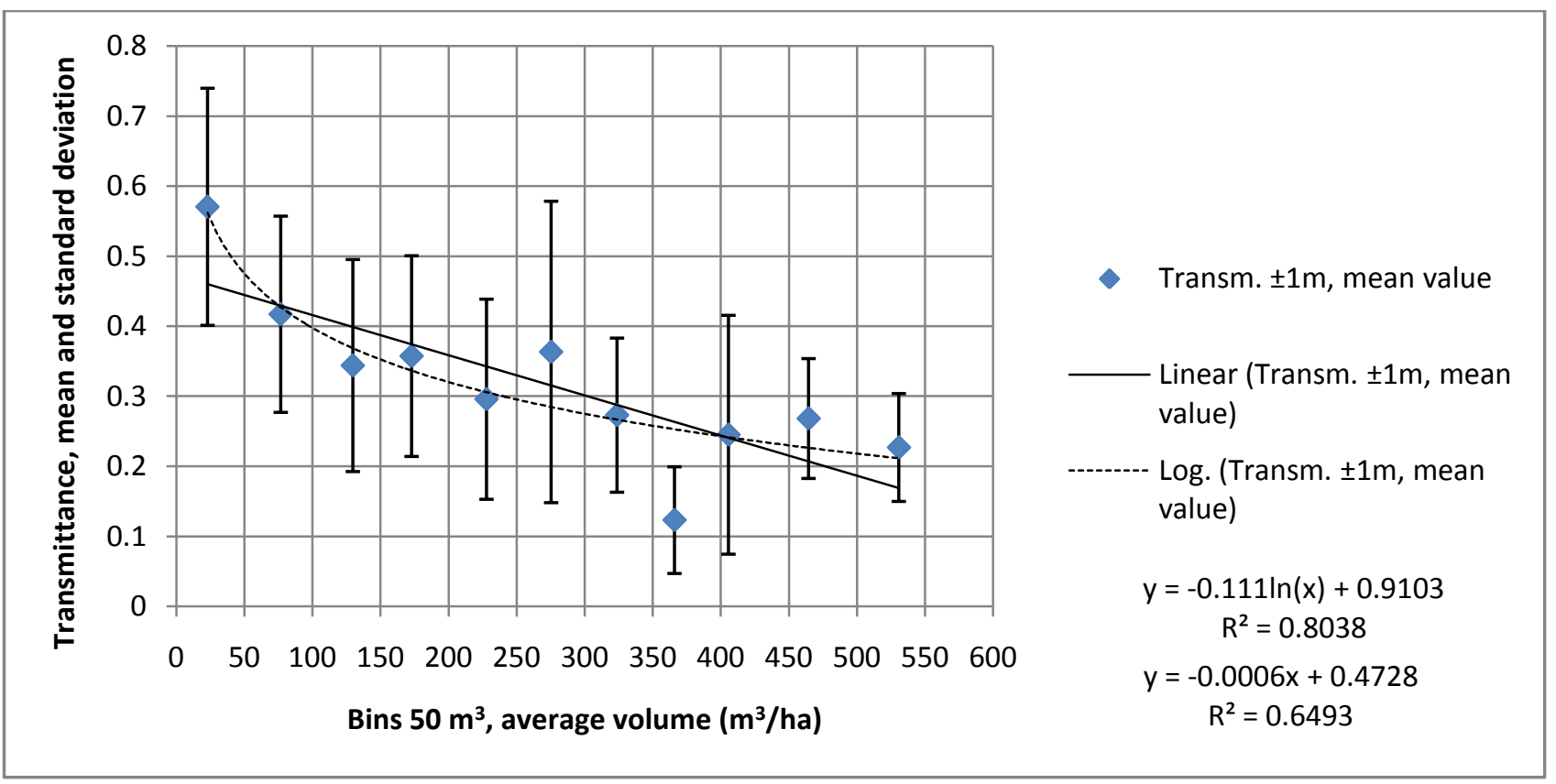

The test plot stem volumes were divided into $50 \mathrm{~m}^{3}$ bins by calculating an average of volumes inside the bin and the mean transmittance for this bin in order to find out the general behavior between these parameters. The results are illustrated in Figures 4-6. The logarithmic curve fits better in the data set giving $\mathrm{R}^{2}$ values $0.70,0.77$, and 0.80 , and thus transmittance depends markedly on the stem volume of the trees. The standard deviation of transmittance varies between the bins because the test plots have different characteristics. Some include trees belonging to only one age class while others have trees and tree species belonging to various age classes and tree species. Also, the homogeneity of the forest plots impacts on the results. We assume that lower transmittances may result from plots having multiple stories (various age classes of trees) and from more homogeneous plots. The plots with the greatest heterogeneity and gaps are expected to manifest the highest transmittances. For example, if a plot consists of $50 \%$ of gaps and $50 \%$ of stem volume of $500 \mathrm{~m}^{3} / \mathrm{ha}$, the transmittance is roughly 0.55 $((1+0.2$ according to Figure 4$) / 2)$, and average volume is $250 \mathrm{~m}^{3} / \mathrm{ha}$. Since deciduous trees are found mainly in mixed stands, the number of totally closed stands was very small and gaps dominated in the obtained transmittances.

Figure 7 includes pulse transmittances from studies by Næsset [6,19] and Solberg et al. [20] for comparison. In the paper presented by Næsset [19], the dates of the laser scannings were 8 June and 9 June 1999, and 6 June 2000, the scan angles were \pm 14 degrees, the pulse density was about 1.1 per $\mathrm{m}^{2}$, and the flight height was $700 \mathrm{~m}$. In the study by Næsset [6], the laser scanning was done on 16 July and 17 July 2001, the flight height was $530-540 \mathrm{~m}$, the average pulse density was $0.84-0.89$ per $\mathrm{m}^{2}$ and pulses transmitted at scan angles greater than 15 degrees were excluded. In the paper presented by Solberg et al. [20], the laser scanning was carried out on 26 July 2005, the flight height was $650 \mathrm{~m}$, and pulses transmitted at scan angles greater than 12 degrees were excluded. The mean values of the transmitted pulses were within the range of 4-5.8 per $\mathrm{m}^{2}$. The vertical line with respect to the mean transmittance shown in the figure is the range of the rate of transmittance through the canopy. The 
forest area in question had been actively managed, it was distinctly divided into stands of various age classes, and it was dominated mostly by Scots pine with a few stands of Norway spruce and deciduous trees. The use of the first pulse model and possibly the lack of understories, were the reasons for the high transmittance values in the study by Solberg et al. [20] when compared to the results of other studies. The data in this study were collected on 25 July 2009 and the scan angles were \pm 15 degrees. The laser scannings for these studies were conducted when the vegetation was in leaf. In general, the levels of transmittances were high, and the transmittance values could have been even higher as the early spring is the primary season for collecting elevation data.

The scanning angles varied from 12 to 15 degrees. The average pulse density between the studies differed significantly, but that was not believed to affect transmittance. The results also showed that by merging transmittance and volume characteristics from previous studies, the general trend was not visible from them. It is also possible that the definition of transmittance (what points are considered as ground points) varies between studies.

The results of Figure 7 also show that there are other forest attributes, depicted in Section 2.4, that impact on transmittance. Table 2 shows their inter-correlation. Moreover, the canopy structure and LAI (Leaf Area Index) are believed to impact on the results, but it is difficult to compare the results between different studies subject to different circumstances. However, the impact of other predictors on transmittance was modeled further. The basal area had the largest single impact on the transmittance model and the mean angle had the least impact (Tables 3 and 4). Table 4 summarizes the results of the linear models. LnTr-models fit better than Tr-models.

Figure 7. Transmittance through the canopy to the ground as a function of stem volume. Comparison of data from this study with the data of three other studies.

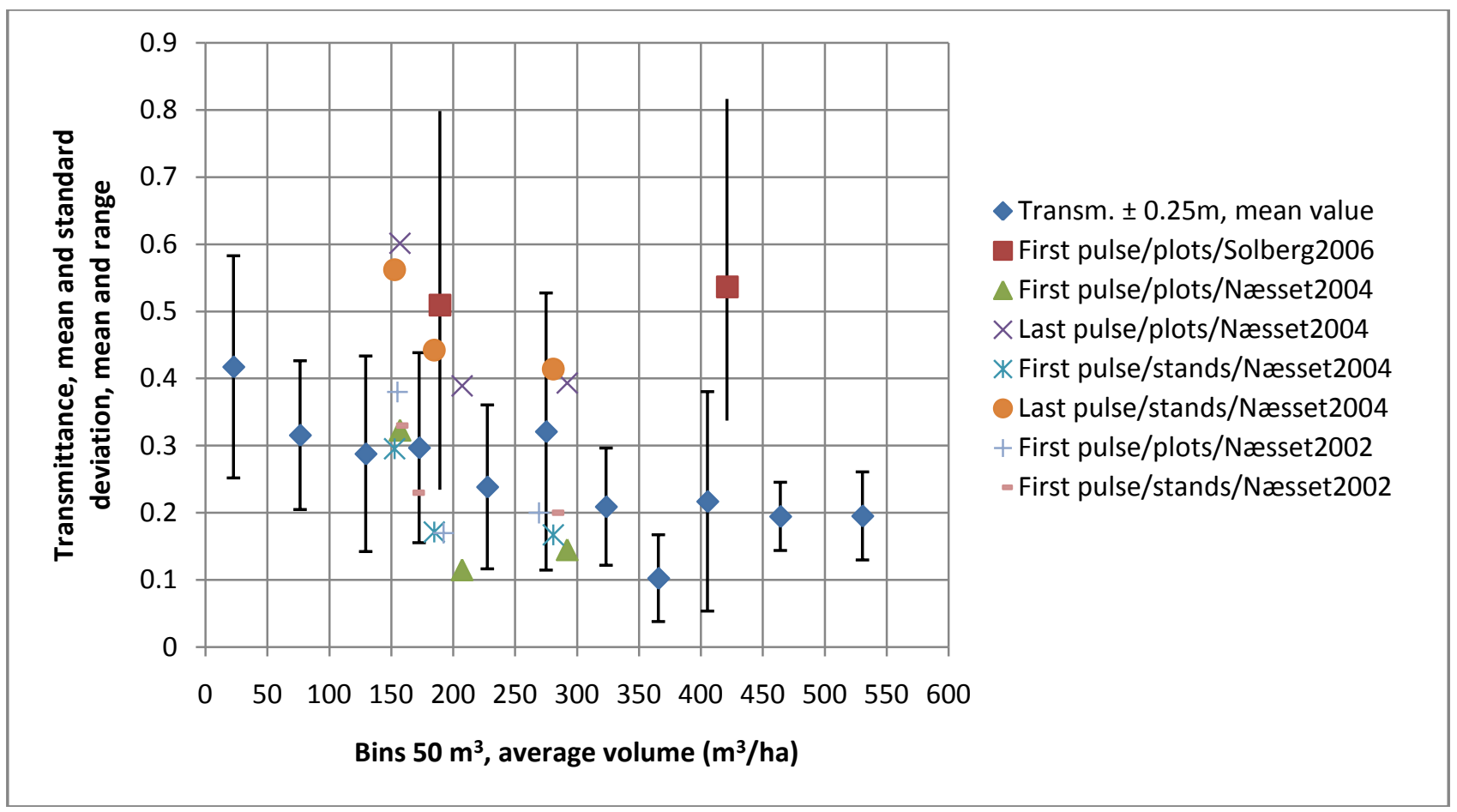


Table 2. The Pearson correlation matrix between the predictor variables.

\begin{tabular}{|c|c|c|c|c|c|}
\hline \multicolumn{6}{|c|}{ Correlation Matrix } \\
\hline & Angle & Height(m) & Diameter(cm) & Basal_area(m²/ha) & Volume $\left(\mathbf{m}^{3} / \mathbf{h a}\right)$ \\
\hline Angle & 1.000 & & & & \\
\hline Height(m) & 0.038 & 1.000 & & & \\
\hline Diameter $(\mathrm{cm})$ & 0.032 & 0.779 & 1.000 & & \\
\hline Basal area(m2/ha) & 0.015 & 0.497 & 0.371 & 1.000 & \\
\hline Volume $\left(\mathrm{m}^{3} / \mathrm{ha}\right)$ & 0.038 & 0.719 & 0.576 & 0.919 & 1.000 \\
\hline
\end{tabular}

Table 3. The regression coefficients for the modeled transmittance.

\begin{tabular}{rrrrrrrrrr}
\hline & \multicolumn{3}{c}{ Ground tolerance level $\mathbf{\pm 0 . 2 5} \mathbf{~ m}$} & \multicolumn{2}{c}{ Ground tolerance level $\mathbf{\pm 0 . 5} \mathbf{~ m}$} & \multicolumn{2}{c}{ Ground tolerance level $\pm \mathbf{1 . 0} \mathbf{~ m}$} \\
& Coef. & $\begin{array}{c}\text { Standard } \\
\text { Error }\end{array}$ & $\begin{array}{c}\text { Standardized } \\
\text { Partial Regr. } \\
\text { Coefficient }\end{array}$ & Coef. & $\begin{array}{c}\text { Standard } \\
\text { Error }\end{array}$ & $\begin{array}{c}\text { Standardized } \\
\text { Partial Regr. } \\
\text { Coefficient }\end{array}$ & Coef. & $\begin{array}{c}\text { Standard } \\
\text { Error }\end{array}$ & $\begin{array}{c}\text { Standardized } \\
\text { Partial Regr. } \\
\text { Coefficient }\end{array}$ \\
\hline b0 & 0.452 & 0.035 & 0 & 0.520 & 0.035 & 0 & 0.563 & 0.035 & 0 \\
b1 & 0.001 & 0.001 & 0.042 & 0.001 & 0.001 & 0.045 & 0.001 & 0.001 & 0.049 \\
b2 & -0.009 & 0.002 & -0.302 & -0.008 & 0.002 & -0.261 & -0.006 & 0.002 & -0.192 \\
b3 & 0.010 & 0.002 & 0.366 & 0.010 & 0.002 & 0.360 & 0.010 & 0.002 & 0.334 \\
b4 & -0.014 & 0.002 & -0.853 & -0.017 & 0.002 & -0.960 & -0.019 & 0.002 & -1.026 \\
b5 & 0.001 & 0.000 & 0.481 & 0.001 & 0.000 & 0.497 & 0.001 & 0.000 & 0.477 \\
\hline
\end{tabular}

Table 4. Summary of the linear models used in the multiple regression analysis. Tr. tolerance_level $=\mathrm{b} 0+\mathrm{b} 1 *$ Angle $+\mathrm{b} 2 * \operatorname{Height}(\mathrm{m})+\mathrm{b} 3 * \operatorname{Diameter}(\mathrm{cm})+$ b4*Basal_area $\left(\mathrm{m}^{2} / \mathrm{ha}\right)+\mathrm{b} 5 * \operatorname{Volume}\left(\mathrm{m}^{3} / \mathrm{ha}\right)$ and $\ln \mathrm{Tr}$. _tolerance_level model.

\begin{tabular}{|c|c|c|c|c|c|}
\hline \multirow[b]{2}{*}{ Tolerance level } & \multirow{2}{*}{$\begin{array}{c}\text { Model } \\
\text { Variables }\end{array}$} & \multicolumn{2}{|c|}{ Tr. } & \multicolumn{2}{|c|}{$\ln T r}$. \\
\hline & & $\mathbf{R}^{2}$ & $\begin{array}{c}\text { Standard } \\
\text { Error }\end{array}$ & $\mathbf{R}^{2}$ & $\begin{array}{c}\text { Standard } \\
\text { Error }\end{array}$ \\
\hline \multirow{6}{*}{ $\pm 0.25 \mathrm{~m}$} & All 5 & 0.278 & 0.131 & 0.375 & 0.444 \\
\hline & Angle & 0.002 & 0.154 & 0.004 & 0.558 \\
\hline & Height & 0.009 & 0.153 & 0.008 & 0.557 \\
\hline & Diameter & 0.008 & 0.153 & 0.019 & 0.554 \\
\hline & Basal area & 0.181 & 0.139 & 0.227 & 0.491 \\
\hline & Volume & 0.095 & 0.146 & 0.118 & 0.525 \\
\hline \multirow{6}{*}{ $\pm 0.5 \mathrm{~m}$} & All 5 & 0.357 & 0.134 & 0.443 & 0.408 \\
\hline & Angle & 0.003 & 0.166 & 0.004 & 0.543 \\
\hline & Height & 0.010 & 0.165 & 0.008 & 0.542 \\
\hline & Diameter & 0.008 & 0.165 & 0.020 & 0.539 \\
\hline & Basal area & 0.248 & 0.144 & 0.285 & 0.460 \\
\hline & Volume & 0.132 & 0.155 & 0.150 & 0.501 \\
\hline \multirow{6}{*}{ $\pm 1.0 \mathrm{~m}$} & All 5 & 0.426 & 0.133 & 0.492 & 0.382 \\
\hline & Angle & 0.003 & 0.175 & 0.004 & 0.532 \\
\hline & Height & 0.009 & 0.175 & 0.008 & 0.531 \\
\hline & Diameter & 0.006 & 0.175 & 0.018 & 0.529 \\
\hline & Basal area & 0.312 & 0.145 & 0.333 & 0.436 \\
\hline & Volume & 0.169 & 0.160 & 0.178 & 0.484 \\
\hline
\end{tabular}


In Table 3 we can see the standardized partial regression coefficients. They indicate the effect of each independent variable on the dependent variable. Basal area has the largest effect, volume the second, diameter the third, height the fourth, and angle the fifth largest effect on the transmittance. In Table 5 the correlation of regression coefficients is depicted.

Table 5. The correlation matrix of the regression coefficients.

\begin{tabular}{|c|c|c|c|c|c|c|}
\hline & b0 & b1 & b2 & b3 & b4 & b5 \\
\hline b0 & 1.000 & & & & & \\
\hline b1 & 0.007 & 1.000 & & & & \\
\hline b2 & -0.673 & 0.014 & 1.000 & & & \\
\hline b3 & -0.179 & 0.007 & -0.498 & 1.000 & & \\
\hline b4 & -0.766 & 0.053 & 0.426 & 0.175 & 1.000 & \\
\hline b5 & 0.780 & -0.055 & -0.568 & -0.176 & -0.934 & 1.000 \\
\hline
\end{tabular}

Since the basal area influenced the transmittance, the relationship between the transmittance and the scanning angle was investigated by class of basal area. Then the scanning angle effect was investigated using test plots with a similar canopy condition. We divided the data into seven classes according to basal area, and the relationship between the transmittance and the scanning angle was further investigated within each basal area class. The coefficient of determination $\left(\mathrm{R}^{2}\right)$ and the standard error were expressed on three ground tolerance levels. The results are shown in Table $6 . \mathrm{R}^{2}$ values range from 0.001 to 0.06 in the seven basal area classes. The transmittance and the scanning angle have the largest $\mathrm{R}^{2}$ values in the basal area class $35-50 \mathrm{~m}^{2} /$ ha, although the values are small.

Table 6. The relationship between the transmittance and the scanning angle in seven basal area (BA) classes.

\begin{tabular}{ccccccc}
\hline $\begin{array}{c}\text { Basal area } \\
\text { class }\left(\mathbf{m}^{\mathbf{2}} \mathbf{h a}\right)\end{array}$ & $\begin{array}{c}\text { Ground tolerance level } \\
\mathbf{\pm 0 . 2 5} \mathbf{~ m}\end{array}$ & $\begin{array}{c}\text { Ground tolerance level } \\
\mathbf{\pm 0 . 5} \mathbf{~ m} \\
\end{array}$ & $\mathbf{R}^{\mathbf{2}}$ & Standard Error & $\mathbf{R}^{\mathbf{2}}$ & $\begin{array}{c}\text { Ground tolerance } \\
\text { Standard Error } \\
\text { level } \mathbf{\pm 1 . 0} \mathbf{~ m} \\
\text { Standard } \\
\text { Error }\end{array}$ \\
\hline $5 \leq \mathrm{BA}<10$ & 0.007 & 0.133 & 0.006 & 0.146 & 0.004 & 0.143 \\
$10 \leq \mathrm{BA}<15$ & 0.003 & 0.147 & 0.004 & 0.147 & 0.004 & 0.147 \\
$15 \leq \mathrm{BA}<20$ & 0.001 & 0.139 & 0.001 & 0.140 & 0.001 & 0.140 \\
$20 \leq \mathrm{BA}<25$ & 0.001 & 0.148 & 0.002 & 0.153 & 0.003 & 0.152 \\
$25 \leq \mathrm{BA}<30$ & 0.037 & 0.139 & 0.032 & 0.146 & 0.027 & 0.148 \\
$30 \leq \mathrm{BA}<35$ & 0.001 & 0.116 & 0.003 & 0.126 & 0.004 & 0.131 \\
$35 \leq \mathrm{BA}<50$ & 0.060 & 0.084 & 0.052 & 0.093 & 0.051 & 0.098 \\
\hline
\end{tabular}

It seems that canopy characteristics dominate the transmittance process in boreal forests with scanning angles less than 15 degrees. With significantly larger angles, it is obvious that the effect of scanning angle is significant. Thus, there is an urgent need for research determining the scanning angle 
whereby the scan angle and forest characteristics have equal effect on transmittance in dense boreal forests. That level could be considered as being the maximum acceptable scanning angle. In our study, we did not see any indication of that level being reached and therefore we, recommend increasing the applied scanning angle - from the point of view of elevation modeling in boreal forests. However, we do not know how much the scanning angle can be increased. Increasing the scanning angles also provides new possibilities for nationwide laser scanning data collection and for simultaneously collecting scanning and imaging data even in the forested environment.

The quality of elevation modeling deteriorates slowly as a function of transmittance. According to Hyyppä et al. [10], if the accuracy of elevation modeling needs to be improved by $50 \%$, the number of pulses needs to be roughly increased by about 10 times. If this is applied to the results of this study, a transmittance of $10 \%$ indicates the doubling of the elevation error in these parts of the elevation model and if further reduction in elevation error accuracy can be accepted, higher scanning angles can be accepted for elevation modeling.

The effect of scanning angle on forest information retrieval accuracy cannot be directly predicted based on results of our study since the applied forest inventory technique and ground elevation modeling are differently affected by the scanning angle. Approaches to deriving forest information from airborne laser scanning data has been conventionally divided into two groups; those based on statistics of canopy height (referred to as area-based techniques), and those based on individual tree detection (referred to as individual-tree or single-tree-based techniques). Presently, area-based techniques are operationally applied in the Nordic Countries in standwise forest inventorying. Since area-based estimation is mainly based on features derived using also the penetration capability of beams (density-based features and percentiles), the effect of scanning angle on area-based inventory is expected to be more significant. In general, it can be seen that an increase in scanning angle will cause an increase in the general point cloud height level, which is interpreted as an increase in volume and basal area. In individual tree detection, the delineation of individual trees and the detection rate of individual trees is hampered when the scanning angle is increased and the trees are seen only from one side. Thus, in forest applications, there is a need for further study of the effects of the scanning angle.

\section{Conclusions}

In this study, we investigated ALS transmittance as a function of scanning angles in a boreal forest area. With a database of about 450 real transmittance samples from the air and by comparing them to the field data composed of the main forest attributes, we concluded that the characteristics of trees determine the number of the transmitted pulses penetrating down to the ground level.

The scanning angle does not have a statistically significant impact on the penetrability of the boreal forest in the study when using scanning angles from 0 to 15 degrees. From this point of view, it appears feasible in future to increase the scanning angle in elevation modeling in boreal conditions when aiming at lower production costs and if some local shadowed areas are acceptable. These shadowed areas are not visible in the average number of ground echoes. By increasing the scanning angle, it is also possible to perform laser scanning and digital aerial photography simultaneously, and to do so even over forested areas, this opens up further implementation possibilities. Further studies are needed regarding larger scanning angles as it is possible that transmittance is considerably more 
influenced by larger scanning angles. Also, the effect of scanning angle on forest inventory requires further studies as is pointed out in Chapter 3.

\section{Acknowledgements}

The Tekes project 'Development of Automatic, Detailed 3D Model Algorithms for Forests and Built-up Areas' and the Academy of Finland project "Science and Technology towards Precision Forestry" are acknowledged for their financial support. The input of HAMK University of Applied Sciences is acknowledged in regard to carrying out of the field measurements.

\section{References}

1. Lohr, U. DEM Generation using laserscanning. In EARSeL Advances in Remote Sensing Yearbook; Vaughan, R., Ed.; EARSeL: Paris, France, 1997; pp. 31-36. Available online: http://www.earsel.org/Advances/5-1997-Yearbook/5_03_Lohr.pdf (accessed on 18 May 2011).

2. Hyyppä, J.; Schardt, M.; Haggrén, H.; Koch, B.; Lohr, U.; Scherrer, H.U.; Paananen, R.; Luukkonen, H.; Ziegler, M.; Hyyppä, H.; Pyysalo, U.; Friedländer, H.; Uuttera, J.; Wagner, S.; Inkinen, M.; Wimmer, A.; Kukko, A.; Ahokas, E.; Karjalainen, M. HIGH-SCAN: The first European-wide attempt to derive single-tree information from laser scanner data. Photogramm. J. Fin. 2001, 17, 58-68.

3. Ahokas, E.; Kaartinen, H.; Matikainen, L.; Hyyppä, J.; Hyyppä, H. Accuracy of High-Pulse-Rate Laser Scanners for Digital Target Models. In Observing Our Environment from Space. New solutions for a New Millennium, Proceedings of the 21st EARSeL Symposium, Paris, France, 14-16 May 2001; Begni, G., Ed.; Balkema Publishers: Rotterdam, The Netherlands, 2002; pp. 175-178.

4. Reutebuch, S.; McGaughey, R.; Andersen, H.-E.; Carson, W. Accuracy of a high-resolution lidar terrain model under a conifer forest canopy. Can. J. Remote Sens. 2003, 29, 527-535.

5. Chasmer, L.; Hopkinson, C.; Treitz, P. Investigating laser pulse penetration through a conifer canopy by integrating airborne and terrestrial lidar. Can. J. Remote Sens. 2006, 32, 116-125.

6. Næsset, E. Effects of different flying altitudes on biophysical stand properties estimated from canopy height and density measured with a small-footprint airborne scanning laser. Remote Sens. Environ. 2004, 91, 243-255.

7. Hyyppä, J.; Hyyppä, H.; Yu, X.; Kaartinen, H.; Kukko, A.; Holopainen, M. Forest inventory using small-footprint airborne lidar. In Topographic Laser Ranging and Scanning. Principles and Processing; Shan, J., Toth, C., Eds.; CRC Press: Boca Raton, FL, USA, 2009; pp. 333-370.

8. Sithole, G.; Vosselman, G. Experimental comparison of filter algorithms for bare Earth extraction from airborne laser scanning point clouds. ISPRS J. Photogramm. Remote Sens. 2004, 59, 85-101.

9. Kobler, A.; Pfeifer, N.; Ogrinc, P.; Todorovski, L.; Ostir, K.; Dzeroski, S. Repetitive interpolation: A robust algorithm for DTM generation from aerial laser scanner data in forested terrain. Remote Sens. Environ. 2007, 108, 9-23.

10. Hyyppä, H.; Yu, X.; Hyyppä, J.; Kaartinen, H.; Kaasalainen, S.; Honkavaara, E.; Rönnholm, P. Factors Affecting the Quality of DTM Generation in Forested Areas. In ISPRS Workshop Laser Scanning 2005, Enschede, The Netherlands, 12-14 September 2005. 
11. Ahokas, E.; Yu, X.; Oksanen, J.; Hyyppä, J.; Kaartinen, H.; Hyyppä, H. Optimization of the Scanning Angle for Countrywide Laser Scanning. In ISPRS Workshop Laser Scanning 2005, Enschede, the Netherlands, 12-14 September 2005; Vosselman, G., Brenner, C. Eds.; In The International Archives of Photogrammetry, Remote Sensing and Spatial Information Sciences; ISPRS: Vienna, Austria, 2005; Vol. XXXVI, part 3/W19, pp. 115-119.

12. $\mathrm{Su}, \mathrm{J}$; Bork, E. Influence of vegetation, slope and Lidar sampling angle on DEM accuracy. Photogramm. Eng. Remote Sensing 2006, 72, 1265-1274.

13. Holmgren, J.; Nilsson, M.; Olsson, H. Simulating the effects of lidar scanning angle for estimation of mean tree height and canopy closure. Can. J. Remote Sens. 2003, 29, 623-632.

14. Morsdorf, F.; Frey, O.; Meier, E.; Itten, K.; Allgöwer B. Assessment of the influence of flying altitude and scan angle on biophysical vegetation products derived from airborne laser scanning. Int. J. Remote Sens. 2008, 29, 1387-1406.

15. Ahokas, E.; Hyyppä, J.; Kaartinen, H.; Kukko, A.; Kaasalainen, S.; Krooks, A. The effect of biomass and scanning angle on laser beam transmittance. In International Archives of Photogrammetry, Remote Sensing and Spatial Information Sciences; ISPRS: Vienna, Austria, 2010; Vol. XXXVIII(7A), pp. 1-6.

16. Holopainen, M.; Haapanen, R.; Tuominen, S.; Viitala, R. Performance of Airborne Laser Scanning- and Aerial Photograph-Based Statistical and Textural Features in Forest Variable Estimation. In Proceedings of Silvilaser 2008, Edinburgh, UK, 17-19 September 2008.

17. Laasasenaho, J. Taper curve and volume functions for pine, spruce and birch. Communicationes Instituti Forestalis Fenniae 1982, 108, 74.

18. Axelsson, P. DEM Generation from Laser Scanner Data Using Adaptive TIN Models. In Proceedings of XIXth Congress, TC IV, Amsterdam, the Netherlands, 16-23 July 2000; In The International Archives of Photogrammetry, Remote Sensing and Spatial Information Sciences; ISPRS: Vienna, Austria, 2001; Vol. XXXIII, part 4B, pp. 110-117.

19. Næsset, E. Predicting forest stand characteristics with airborne scanning laser using a practical two-stage procedure and field data. Remote Sens. Environ. 2002, 80, 88-99.

20. Solberg, S.; Næsset, E.; Hansen, K.H.; Christiansen, E. Mapping defoliation during severe insect attack on Scots pine using airborne laser scanning. Remote Sens. Environ. 2006, 102, 364-376.

(C) 2011 by the authors; licensee MDPI, Basel, Switzerland. This article is an open access article distributed under the terms and conditions of the Creative Commons Attribution license (http://creativecommons.org/licenses/by/3.0/). 